\title{
The Differentiation and Pedagogical Application of Near-synonyms Baochi and Weichi
}

\author{
JungChih Tsai ${ }^{1, a^{*}}$, ChingChih Tsai ${ }^{2, b}$ \\ ${ }^{1}$ School of Humanities, Minjiang University, Fuzhou City, Fujian Province, China. \\ ${ }^{2}$ Institute of Applied English, National Taiwan Ocean University, Keelung, Taiwan \\ a*jungchih99@qq.com \\ b ching2005@gmail.com
}

\begin{abstract}
The study aims at differentiating the near-synonymous pair Baochi from Weichi. The corpus-based analysis approach and the relative Chinese dictionaries are used to analyze the data collected from Academia Sinica Corpus and Chinese Word Sketch. Six aspects are discussed, including the syntactic patterns, semantic characteristics, semantic roles, collocations, and the functions of pragmatics and discourse. Finally, this study provides teaching recommendations by combining Chinese pedagogical grammar principles.
\end{abstract}

Keywords: Near-Synonyms, baochi, weichi, pedagogical application

\section{近义词 “保持” 和 “维持” 的辨析及教学应用}

蔡蓉芝 ${ }^{1,}$ a*蔡菁芝 ${ }^{2,}$ b

1 闽江学院人文学院, 福州, 福建, 中国

2 海洋大学应用英语研究所, 基隆, 台湾

a*jungchih99@qq.com

b ching2005@gmail.com

\section{摘要}

本文旨在辨析近义词 “保持”、“维持” 的异同。从句式结构、语义特征、语义指涉、词语搭配、语用层面、篇 章功能进行探讨。结果显示, 二词同样作为谓语动词, 后可接宾语, 亦能宾语前移后接补语或后不接补语, 也 可当定语，尚有名物化的用法。语义特征上，表示情状的持续，二者皆可表现 “进行貌、完成貌”，“保持” 的 积极性较高。语义指涉上：语义重点指向 “宾语”，如 “宾语” 前移，语义重点指向 “补语”。“保持” 最常搭 配各种人物状态与抽象心理感受的词语, “维持” 最常搭配各种外在状态词语, 二者之篇章功能均为带出焦点 信息。文末, 本文结合汉语教学语法原则, 提出教学建议。

关键词: 近义词, 保持, 维持, 教学应用

\section{1. 前言}

“保持”、“维持” 在《汉语水平词汇与汉字等级 大纲》(以下简称《词汇大纲》) 里, 分属乙级词与丙 级词。本文的前半研究检视了 6 本分别收录“保持”、 “维持” 的中高级教材, 又检视了 7 本近义词词典或 线上汉语词典, 6 本教材为: 《今日台湾》、《博雅汉语》、 《思想与社会》、《实用汉语课本》、《中文突破》、《中 国文化从谈》。7 本词典为: 《现代汉语用法辞典》、 《1700 对近义词语用法对比》、《汉语近义词辞典》、 《学汉语用例辞典》、《汉语近义词用法词典》、《教育
部重编国语辞典修订本 (网络版)》、《在线新华字典》。 教材或辞典里, 中文批注或英文批注, 两词的解释相 近, 学习者若要判断二词的差异, 并正确使用, 恐怕 不易。本文又进行了使用者（台陆母语者和外籍学习 者) 调查, 结果显示母语者的认知也有落差, 也不能 完全符合预设答案 (见下图 1), 外籍学习者呈现习得 不规律, 也受到所在地区影响, 显见近义词教学之必 要。本文透过语料库的分析, 探讨这两个词语在句法、 语义及语用上的差异，提供国际汉语教师解释这两个 近义词的参考依据, 并参考汉语教学语法原则 (邓守 信, 2008), 提出国际汉语教学的排序建议。 
200

母语者回答符合率百分比

0

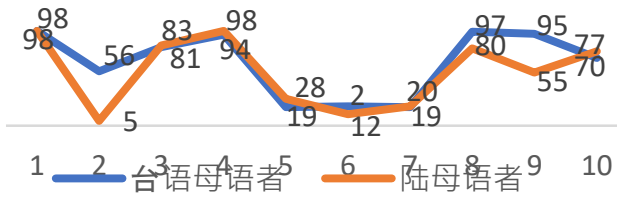

图 1 “保持、维持”台陆母语者使用调查

\section{2. 句法功能}

本段从句法功能层面来分析语料。表 1 是“保持”、 “维持” 在《词汇大纲》的级别, 在中研院现代汉语 语料库中的词频统计排序、词频百分比、语料笔数, 以及在北大现代汉语语料库的笔数。

\section{表 1 “保持、维持” 之语料库各类数据}

\begin{tabular}{|c|c|c|c|c|c|}
\hline \multirow{2}{*}{ 数据源 } & \multirow{2}{*}{$\begin{array}{l}\text { 《汉语 } \\
\text { 水平词 } \\
\text { 汇与汉 } \\
\text { 字等级 } \\
\text { 大纲》 }\end{array}$} & \multicolumn{3}{|c|}{ 中研院现代汉语平衡语料库 } & \multirow{2}{*}{$\begin{array}{l}\text { 北大现 } \\
\text { 代汉语 } \\
\text { 语料库 } \\
\text { Count }\end{array}$} \\
\hline & & $\begin{array}{l}\text { 词频 } \\
\text { 排序 } \\
\text { No/Rank }\end{array}$ & $\begin{array}{l}\text { 词频 } \\
\text { Percent }\end{array}$ & $\begin{array}{l}\text { 笔数 } \\
\text { Count }\end{array}$ & \\
\hline $\begin{array}{l}\text { 保持 VJ } \\
\mathrm{Nv}\end{array}$ & 乙 & $\begin{array}{l}583 / 1061 \\
34 / 12064\end{array}$ & $\begin{array}{l}0.012 \% \\
0.001 \%\end{array}$ & 1139 & 40463 \\
\hline $\begin{array}{l}\text { 维持 } \\
\mathrm{VJ}, \\
\mathrm{Nv} \\
\mathrm{VJ}+\mathrm{vrv}\end{array}$ & 丙 & $\begin{array}{l}753 / 785 \\
18 / 19413 \\
2 / 70282 \\
\end{array}$ & $\begin{array}{l}0.015 \% \\
0.000 \% \\
0.000 \% \\
\end{array}$ & 1611 & 11037 \\
\hline
\end{tabular}

各有 1139、1611 笔, 在 “北大语料库” 现代汉语语 料中各有 40463、11037 笔, 中研院语料库收录丙级 词 “维持” 的语料多于乙级词 “保持” , 这是语料库 主要收录书面语产生的现象。将两个词在两个语料库 中, 各取前 250 笔语料, 每一词取得总语料 500 笔, 比较句法功能之差异。删除重复的语料, “保持、维 持” 各有 490、482 笔。

表 2 “保持、维持” 之句法功能分布情形

\begin{tabular}{|c|c|c|c|c|c|}
\hline 可 & \multicolumn{3}{|c|}{ 谓语 } & \multirow[t]{2}{*}{ 定语 } & \multirow{2}{*}{$\begin{array}{c}\text { 名物 } \\
\text { 化 }\end{array}$} \\
\hline $\begin{array}{l}\text { 词条 } \\
\text { 笔数 }\end{array}$ & $\begin{array}{l}\text { 后接 } \\
\text { 宾语 }\end{array}$ & $\begin{array}{c}\text { 宾语前 } \\
\text { 移后接 } \\
\text { 补语 }\end{array}$ & $\begin{array}{l}\text { 宾语前 } \\
\text { 移后不 } \\
\text { 接补语 }\end{array}$ & & \\
\hline $\begin{array}{c}\text { 保持 } \\
490 \\
\end{array}$ & $\begin{array}{l}417 \\
85.1 \% \\
\end{array}$ & $\begin{array}{l}28 \\
5.7 \% \\
\end{array}$ & $\begin{array}{l}13 \\
2.7 \% \\
\end{array}$ & $\begin{array}{l}24 \\
4.9 \%\end{array}$ & $\begin{array}{l}8 \\
1.6 \% \\
\end{array}$ \\
\hline $\begin{array}{c}\text { 维持 } \\
482 \\
\end{array}$ & $\begin{array}{l}412 \\
85.5 \%\end{array}$ & $\begin{array}{l}29 \\
6 \% \\
\end{array}$ & $\begin{array}{l}28 \\
5.8 \% \\
\end{array}$ & $\begin{array}{l}11 \\
2.3 \% \\
\end{array}$ & $\begin{array}{l}2 \\
0.4 \% \\
\end{array}$ \\
\hline
\end{tabular}

由表 3 可看出, “保持”、“维持” 在句中充当谓 语动词、定语、名物化成分, 主要担任谓语动词。
表 3: “保持、维持” 句法功能、句式、例句

\begin{tabular}{|c|c|c|}
\hline & 保持 & 维持 \\
\hline 谓语 & 人/物/事/状态十（以/来） & 人/物/事/状态十（以/来） \\
\hline 动词 & ＋保持＋感受/状态/事 & +维持＋感受/状态/事 \\
\hline -后 & & \\
\hline 接宾 & 例: 绩效及管理都能创 & 例：妻子去船主家当奶 \\
\hline & 新, 以保持其位于不坠 & 娘, 以维持一家人的生 \\
\hline (最常 & 之地。 & \\
\hline 用) & $\begin{array}{l}\text { 事物/状态 +使 }+人 / \text { 物 } \\
\text { +保持+状态 } \\
\text { 作息正常和不间断的运 } \\
\text { 动, 使他保持充沛体力。 }\end{array}$ & $\begin{array}{l}\text { 事物/状态+使+物+维 } \\
\text { 持+状态 } \\
\text { 钙质可以使身体维持正 } \\
\text { 常的弱碱性体质。 }\end{array}$ \\
\hline 动词 & ... (使) +十状态/物+ & ... (使) +状态/物十 \\
\hline $\begin{array}{l}\text { 一宾 } \\
\text { 语前 }\end{array}$ & $\begin{array}{l}\text { 保持＋状态/时量/方 } \\
\text { 向 }\end{array}$ & $\begin{array}{l}\text { 维持十状态/时量/方 } \\
\text { 向 }\end{array}$ \\
\hline 移后 & 例: 人类应该使空气 & 例：封建制度开始崩 \\
\hline $\begin{array}{l}\text { 接补 } \\
\text { 语 } \\
\end{array}$ & 保持清洁。 & $\begin{array}{l}\text { 溃, 贵族的统治权渐 } \\
\text { 渐维持不住了。 }\end{array}$ \\
\hline 动词 & 事物+时间副词/能 & 事物+时间副词/能 \\
\hline 一宾 & 愿 $\mathbf{V}+$ 保持 & 愿 $\mathbf{V}+$ 维持 \\
\hline 语前 & 例: 这项成果应继续 & 例: 经济基础不乱, 局 \\
\hline 移后 & 保持 & 面还能维持。 \\
\hline 不接 & 事物十由十人+（所） & 事物 $+\mathbf{V}+\mathrm{S}+$ 来 + \\
\hline 补语 & 十保持 & 维持 \\
\hline & 例：撑竿跳纪录是 & 例：太多利益必须仰 \\
\hline & $\begin{array}{l}5.62 \text { 米, 由...梁学仁 } \\
\text { 保持。 }\end{array}$ & 赖高屏溪来 \\
\hline 定语 & $\begin{array}{l}\sim+\text { 保持 (的) }+\mathbf{N} \\
\text { 例: 纪录保持人、泰人 } \\
\text { 保持的传统节日很 } \\
\text { 多。 }\end{array}$ & $\begin{array}{l}\sim+\text { 维持 (的) }+\mathbf{N} \\
\text { 例: 活动维持费、他的 } \\
\text { 话划破开饭后一直维 } \\
\text { 持的沉默。 }\end{array}$ \\
\hline $\begin{array}{l}\text { 名物 } \\
\text { 化 }\end{array}$ & $\begin{array}{l}\mathbf{N +} \text { (的) +保持 } \\
\text { 种树 ... 提升空气质 } \\
\text { 量, 做好水土保持 }\end{array}$ & $\begin{array}{l}\mathrm{N}+\text { 的+维持 } \\
\text { 例: 实有碍社会和谐 } \\
\text { 的维持 }\end{array}$ \\
\hline
\end{tabular}

\section{1. “保持”、“维持” 后接宾语}

“保持”、“维持”后接宾语所占的总比例为 $85.1 \% 、 85.5 \%$ ，是最常用的基本句式。

“保持” 的宾语如: 距离、状态、优势、心情、 态度、关系..., 抽象名词较多。“维持”的宾语有: 现状、秩序、生计、生命、质量、形象..., 有抽象与 具体名词。“保持”后的宾语有关 “情绪”、“心境”, 如：冷漠、欢喜心，也可以是保持 “纪录” ，但 “维 持” 没有这种用法。“维持” 的宾语如: 生计、生命、 生活等，这类词语就不与 “保持” 搭配。

\section{2 “保持”、“维持” 宾语前移, 后接补语}

“保持”、“维持” 宾语前移, 后接补语, 所占的 总比例很低, 各为 $5.7 \% 、 6 \%$, 语料数分别为 $28 、 29$ 笔，其句式是: “.... (使) +状态/物十保持/维持十状 态/时量/方向”。二者在这类句式上, 没有差异, 使 用比例也差不多。 


\section{3 “保持”、“维持” 宾语前移, 后不接补语}

“保持”、“维持” 宾语前移, 后不接补语情形, 所占的总比例也低, 各为 $2.7 \% 、 5.8 \%$, 语料数各为 17、28 笔。二词的这种句式明显不同, 保持的一类句 式是藉着 “由” 使宾语置于主语前端, 如: “原纪录 由五八年的巴尔的摩子弹队所保持”, 另一类则加上 经常性或持续性的时间副词, 如: “但形式上的尊严 总还保持着”。“维持” 的句式使用能愿动词, 如: “连正常的经费都难以维持”、“但是补偿性公正得 以维持”, 另一句式用 “来”, 如: “一家人的生活 基本都依靠儿子做木匠活来维持”。

\section{4. “保持”、“维持”当定语}

“保持”、“维持”当定语分别占总比例的 $4.9 \%$ 、 $2.3 \%$ ，语料笔数各为 $24 、 11$ 笔。“保持” 当定语的 比例多 “维持”一倍。

当定语的句式: + 保持/维持 (的) $+\mathrm{N}$ “保持” 当定语有 10 笔是 “水土保持 $+\mathrm{N}$ ”, 有 7 笔是 “人” 保持的 “记录” ; “维持有 7 笔是 “...维持费” ，其 中 5 笔是 “活动维持费” , 二者在当定语时, 有比较 固定的用法，搭配词语上明显有差异。

\section{5. “保持”、“维持” 名物化}

“保持” 有 8 例, “维持” 有 2 例名物化的用 法，各占总笔数 $1.8 \% 、 0.4 \%$ 。

“保持” 有 6 例都是 “水土保持” ， “维持” 的 一例是 “实有碍社会和谐的维持” , 另一例则是口号 式的 “激励重于维持” ，扩大语料库搜寻 “（的）+ 维持” , 在中研院平衡语料库里搜寻一千笔的数据, “保持” 名物化的用法增加了 4 笔语料, 全都是 “水 土保持” , “维持” 也只增加了 4 笔语料, 名物化的 使用情形确实很低, 尤其, “保持” 倾向固定与 “水 土” 搭配，“…的保持”仅出现一例。

\section{6. 小结}

“保持”、“维持” 的常用句式是后接宾语, 其次 为宾语前移后接补语, 各种句式使用情形依序为:

后接宾语 $>$ 宾语前移后接补语 $>$ 宾语前移后不 接补语句式 $>$ 定语 $>$ 名物化

“保持” 后不接补语的使用比例较 “维持” 低, “保持” 定语、名物化的使用比例都高于 “维持”。

\section{3. 语义分析}

“保持”、“维持” 在词典的基本语义: “保持”, 保护支持, 有使状况局面继续不变的意思, 或维持原 状使不消失或减弱。“维持”, 维护支持, 有使原状况、 局面不变、继续存在、保持的意思。也有解释相矛盾 处, 《汉语近义词辞典》: “维持” 有比较勉强的, 被动 的, 不得不继续下去的意思, 《汉语近义词用法词典》:
“维持”为积极保护某事物; 《学汉语用例辞典》说 “保持” 的对象多是抽象名词，《1700 对近义词语用 法对比》则说 “维持” 的对象是抽象名词。本段探讨 其语义特性，第一为二词在时间上的特性，第二为“语 义指涉”，探讨其语义重点指向主语、补语或宾语。

\section{1. 时间动态助词与时间状语}

本段探讨 “保持”、“维持” 与时间标志 “了、着、 过” 搭配的情形，也探讨与助动词 “会、能（够）、 可以、要” 以及副词 “仍 (然)、一直、始终、永远” 搭配的情形。“会” 在此处如同 “将”, “能”指 “能 够”, “可以”此处是 “能”，“会、能（够）、可 以、得以”表推测未来, “要”则有对未来期许之意, “仍 (然)、一直、始终、永远” 有表动作持续进行 至末来之意, 故一并比较。

表 4 “保持、维持” 搭配 “了、着、过”

\begin{tabular}{|l|l|l|l|l|}
\hline & 了 & 着 & 过 & 总计 \\
\hline $\begin{array}{l}\text { 保 持 } \\
490\end{array}$ & $14(2.8 \%)$ & $36(7.2 \%)$ & 0 & $50(10 \%)$ \\
\hline $\begin{array}{l}\text { 维 持 } \\
482\end{array}$ & $10(2 \%)$ & $13(2.6 \%)$ & 0 & $23(4.6 \%)$ \\
\hline
\end{tabular}

“保持”、“维持” 搭配的时间动态助词主要为 “着”，表示动作正持续进行；其次搭配 “了”，表 示动作完成或实现，故 “保持”、“维持”后一定有结 果, 可能是时间、物或者状态; “保持”、“维持” 都 不与 “过” 搭配, 不能表示某种 “经验”。

(1) 他的这一纪录保持了 25 年。

（2）...日常生活中，维持着一定的人际规范。

例（1）用 “了”，表示动作的实现，已保持 25 年之久。例 (2) 是 “维持” 加上 “着” 的用法, 表示 “人际规范” 是持续地被采用, 至说话此刻。

表 5 是 “保持”、“维持” 与表预测意助动词搭配 的情形。此处用中研院平衡语料库的总语料。由于表 4 采用原搜集之近五百笔语料, 但出现 0 笔的情形, 故搜寻两语料库各千余笔语料, 确保搜寻结果不受语 料过少影响。因此, 表 5、表 6、表 7, 直接采用中研 院语料库之千余笔总语料进行统计。

表 5 “保持、维持” 搭配 “会、能、可以、得以、要”

\begin{tabular}{|l|l|l|l|l|l|l|}
\hline & 会 & 能-够 & 可以 & 得以 & 要 & 总计 \\
\hline 保 持 & 5 & 60 & 13 & 3 & 36 & 107 \\
1139 & $0.4 \%$ & $5.3 \%$ & $1.1 \%$ & $0.26 \%$ & $3.2 \%$ & $10.26 \%$ \\
\hline 维 持 & 18 & 97 & 21 & 15 & 39 & 190 \\
1611 & $1.1 \%$ & $6 \%$ & $1.3 \%$ & $0.93 \%$ & $2.4 \%$ & $11.73 \%$ \\
\hline \multicolumn{6}{|c|}{ “保持”、“维持”与五个表预测意的词语搭配, }
\end{tabular}

共占总比例的 $10.26 \% 、 11.73 \%$ 。 
表 6 “保持、维持” 搭配 “仍然、一直、始终、永 远”

\begin{tabular}{|l|l|l|l|l|l|}
\hline & 仍 (然) & 一直 & 始终 & 永远 & 总计 \\
\hline 保 持 & 35 & 37 & 9 & 7 & 88 \\
1139 & $3.1 \%$ & $3.3 \%$ & $0.8 \%$ & $0.6 \%$ & $7.7 \%$ \\
\hline 维 持 & 87 & 22 & 5 & 12 & 126 \\
1611 & $5.4 \%$ & $1.4 \%$ & $0.3 \%$ & $0.7 \%$ & $7.8 \%$ \\
\hline
\end{tabular}

“保持”、“维持” 与上述四个频率副词搭配, 占 总比例的 $7.7 \% 、 7.8 \%$ 。“保持” 还与 “随时、时时、 依然、经常、常” 搭配, 计 39 笔, “维持” 还与 “持 续、坚持、需要” 搭配, 计 21 笔。由表 5 、表 6 及其 他搭配的助动词或副词可知, “保持、维持” 的事物, 有部份与时间持续至未来相关。（表 6、表 7 为参考 CWS 统计结果, 只提出数个搭配次数较多的助动词、 频率副词等, 并非将所有可搭配的助动词、频率副词 全数列入统计。)

\section{2 语义指涉}

“保持” 或 “维持” 的后方, 多是人或物保有自 身的特质或状态, 也可能是 “目的” , 用 “为了” 来 连接; 后有表示结果或对比结果的情形, 用 “则” 来 连接。“保持” 或 “维持” 的前后方也有部分是因果 关系, 用 “以、可以、而” 来连接。后接宾语句式, 语义皆指向 “保持、维持” 后的事物、情状。

（3）亲友们担心被牵连, 也开始保持距离。

（4）原本一直从事珠宝行业维持生计。

例 (3)，“保持” 的对象是 “距离”, 例 (4), “生计” 是从事珠宝行业要维持的目的, 语义还是指 向 “维持” 后的 “生计”。

宾语前移, 后接补语的情形下, 语义仍然指向“保 持” 或 “维持” 后的补语, 而不是前移的宾语。

（5）...小心不要让身体着凉, 屋里保持温暖。

(6) 封建制度开始崩溃, 贵族的统治权渐渐维持 不住了。

例（5）补语 “温暖” 是要被维持的状态,例（6） 补语 “不住”, 表示维持的结果, 语义指向落在 “保 持”、“维持”之后的补语上。

宾语前移, 后不接补语的情形下, 语义则指向 “保持”、“维持” 前的宾语。

（7）...皇帝的威严怎样保持呢?

（8）...我们现有的现代化水平能不能维持?

例 (7)、例 (8) 前移的宾语是 “皇帝的威严”、 “现代化水平”, 是要被保持与被维持的状态。

“保持”、“维持” 的事物或情状, 通常是由过去 延续到说话的时间点, 并且倾向延续至未来, 也有可 能是从现在发生持续到未来。下图之实线箭头 “ $\rightarrow$ ” 表示事件实际延续的时间, 虚线箭头 “--”表示事件 可能延续的时间。

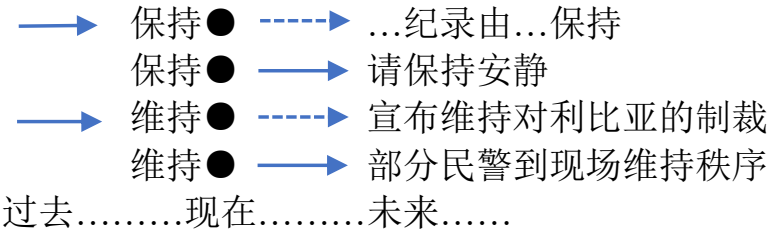

\section{4. 词语搭配}

“保持”、“维持” 在句中主要担任谓语, 本段将 分析其搭配的状语及宾语, 探讨二词是否具有对未来 期许之特性, 使某事物状态持续发展, 并探究其宾语 之特性是具体或抽象, 是否偏向某种类别。

\section{1 搭配之状语}

“保持”、“维持” 前所搭配的状语大多与时间持 续有关, 或者是对未来有期许之词, 如: 继续、仍、 一直、始终、仍然、永远、随时、时时...等。

表 7 根据 CWS 之统计, “保持” 最常搭配 “能、 一直、要、仍” 等词, “维持” 最常搭配 “能、仍、 要、继续”等词, 具体数据如下:

表 7 “保持”、“维持” 搭配之状语

\begin{tabular}{|l|l|l|l|l|l|l|l|l|l|l|l|}
\hline & $\begin{array}{l}\text { 继 } \\
\text { 续 }\end{array}$ & $\begin{array}{l}\text { 希 } \\
\text { 望 }\end{array}$ & 仍 & $\begin{array}{l}\text { 一直 } \\
\text { 始 }\end{array}$ & $\begin{array}{l}\text { 仍 } \\
\text { 然 }\end{array}$ & $\begin{array}{l}\text { 永 } \\
\text { 远 }\end{array}$ & $\begin{array}{l}\text { 随 } \\
\text { 时 }\end{array}$ & $\begin{array}{l}\text { 时 } \\
\text { 时 }\end{array}$ & $\begin{array}{l}\text { 依 } \\
\text { 然 }\end{array}$ & $\begin{array}{l}\text { 经 } \\
\text { 常 }\end{array}$ \\
\hline 保 & 1 & 1 & 2 & 3 & 9 & 1 & 7 & 1 & 8 & 7 & 6 \\
持 & 9 & 2 & 3 & 7 & & 2 & & 3 & & & \\
\hline 维 & 2 & 1 & 7 & 2 & 5 & 8 & 1 & $\theta$ & 0 & $\theta$ & $\theta$ \\
持 & 7 & 7 & 9 & 2 & & & 2 & 2 & & 2 & 1 \\
\hline \hline & 常 & 能 & 要 & 应 & 必 & 还 & 持 & 可 & 会 & 得 & \\
& & & & & 须 & & $\begin{array}{l}\text { 续 } \\
\text { 以 }\end{array}$ & & 以 & \\
\hline 保 & 5 & 5 & 3 & 1 & 6 & 1 & $\theta$ & 1 & 5 & 3 & \\
持 & & 3 & 6 & 0 & & 3 & 2 & 3 & & & \\
\hline 维 & 0 & 8 & 3 & 1 & 1 & 7 & 9 & 2 & 1 & 1 & \\
持 & & 9 & 9 & 6 & 3 & & & 1 & 8 & 5 & \\
\hline
\end{tabular}

表 7 显示 “保持”与 “持续” 搭配是 “ 0 ”，但在 “保持” 1139 笔语料中，发现两笔。“随时、时时、 依然、经常、常” 不与 “维持” 共现, 搜寻 “维持” 1611 笔语料, 发现 “维持” 搭配 2 笔 “随时”、2 笔 “依然”、1 笔 “经常”、1 笔 “常常”, CWS 显然 统计有误差。进 Google 搜寻到今周刊有 “时时维持 好眼力” ，脸书有 “时时维持竞争力”，另有 “念佛 的心常维持几天又退转”, 这些具有持续性、经常性 的时间副词仍然可以与 “维持” 搭配。

\section{2 搭配之宾语}

本段采用从两语料库搜集的语料: 保持 490 笔, 维持 482 笔, 来找出与 “保持”、“维持” 搭配的宾语, 此处之宾语, 摘录出现较多次者, 并摘录明显差异者。 统计数据如下: 
表 8 “保持”、“维持” 搭配之宾语

\begin{tabular}{|c|c|c|c|c|}
\hline 词项 & \multicolumn{2}{|c|}{ 保持 } & \multicolumn{2}{|c|}{ 维持 } \\
\hline 语料 & $\begin{array}{c}\text { 中研院 } \\
\text { 平衡 } \\
\text { 语料库 }\end{array}$ & $\begin{array}{c}\text { 北大 } \\
\text { 语料 } \\
\text { 库 }\end{array}$ & $\begin{array}{c}\text { 中研院 } \\
\text { 平衡 } \\
\text { 语料库 }\end{array}$ & $\begin{array}{c}\text { 北大 } \\
\text { 语料 } \\
\text { 库 }\end{array}$ \\
\hline 平衡 & 8 & 14 & 7 & 9 \\
\hline 距离 & 11 & 4 & 2 & 0 \\
\hline 纪录 & 2 & 17 & 0 & 0 \\
\hline 状态 & 8 & 9 & 0 & 1 \\
\hline 关系 & 8 & 3 & 5 & 0 \\
\hline 态度 & 6 & 2 & 0 & 1 \\
\hline 传统 & 4 & 1 & 2 & 0 \\
\hline 体力 & 2 & 3 & 0 & 0 \\
\hline 水平 & 2 & 2 & 12 & 16 \\
\hline 心情 & 2 & 0 & 0 & 0 \\
\hline 理性 & 2 & 0 & 0 & 0 \\
\hline 信心 & 2 & 0 & 0 & 1 \\
\hline 尊严 & 2 & 0 & 1 & 0 \\
\hline 方式 & 0 & 3 & 4 & 0 \\
\hline 心理 & 2 & 0 & 0 & 0 \\
\hline 利益 & 2 & 0 & 2 & 0 \\
\hline 一贯性 & 2 & 0 & 0 & 0 \\
\hline 活力 & 1 & 1 & 2 & 0 \\
\hline 生命力 & 1 & 1 & 0 & 0 \\
\hline 生命 & 0 & 2 & 4 & 19 \\
\hline 现状 & 1 & 0 & 6 & 1 \\
\hline 秩序 & 0 & 0 & 12 & 9 \\
\hline 生计 & 0 & 0 & 2 & 5 \\
\hline 生活 & 0 & 0 & 9 & 21 \\
\hline 品质 & 0 & 0 & 5 & 0 \\
\hline
\end{tabular}

由表 8 可知，二者的语义重点不同，“保持” 搭 配的宾语偏向抽象的状态、心理感受, 偏向积极、正 向价值，或使主体受益的情状、事物。“维持”搭配的 宾语偏向较具体可见的“秩序、生活”, 也多是正向, 使主体受益，但较缺乏心理积极性。

\section{3. 单独句式搭配之词语}

“保持”、“维持” 在宾语前移, 后不接补语的情 况下，有各自的单独句式。“保持” 的单独句式:

\section{事物十由十人十（所）十保持}

（9）原纪录由五八年的巴尔的摩子弹队所保持。

例 (9) 的 “原纪录” 是宾语在前, “巴尔的摩子 弹队” 是主语, “由” 连接宾语主语, “所” 连接主 语、谓语, “所” 可用可不用。“维持” 的单独句式:

\section{事物 $+\mathrm{V}+\mathrm{S}+$ 来+维持}

（10）一家人的生活基本都依靠儿子做木匠活来 维持。“一家人的生活” 是前置宾语, “儿子做木匠 活” 是主语, “来”用来联系主语与谓语维持。

有一固定短语“水土保持”, 如“水土保持不当”, “水土” 为形式上的主语, 却是深层 “宾语”, 是被 保持的对象，但没有 “保持水土” 的用法。

\section{4. 小结}

本节就 “保持”、“维持” 词语搭配、句式共现进 行分析, 结果整理参见表 9:

表 9 “保持”、“维持”比较

\begin{tabular}{|c|c|c|}
\hline & 保持 & 维持 \\
\hline $\begin{array}{l}\text { 搭配时 } \\
\text { 间动态 } \\
\text { 助词及 } \\
\text { 时间状 } \\
\text { 语 }\end{array}$ & $\begin{array}{l}\text { 1. 搭配 “了、着” } \\
\text { 表动作完成、进行 } \\
\text { 2. 较常搭配 “能、一 } \\
\text { 直、要、仍” }\end{array}$ & $\begin{array}{l}\text { 1. 搭配 “了、着” 表 } \\
\text { 动作完成、进行 } \\
\text { 2. 较常搭配 “能、 } \\
\text { 仍、要、继续” }\end{array}$ \\
\hline $\begin{array}{l}\text { 搭配 } \\
\text { 宾语 }\end{array}$ & $\begin{array}{l}\text { 1. 事物状态, 如: } \\
\text { 状态、关系、距 } \\
\text { 离、平衡、纪录 } \\
\text { 2. 传统、体力、XX } \\
\text { XX 力 } \\
\text { 3. 偏向抽象内在心 } \\
\text { 理感觉, 如: 态度、 } \\
\text { 心情、理性、信心 }\end{array}$ & $\begin{array}{l}\text { 1. 外在的状态, } \\
\text { 如: 水平、秩序、 } \\
\text { 生命、生活 } \\
\text { 2. 平衡、现状、生计 } \\
\text { 3. 偏向较具体可见 } \\
\text { 的状态或事物, } \\
\text { 如: 关系、质量、 } \\
\text { 姿势、方式 }\end{array}$ \\
\hline $\begin{array}{l}\text { 搭配 } \\
\text { 主语 }\end{array}$ & 1. 人>事物、状态 & 1. 人>事物、状态 \\
\hline $\begin{array}{l}\text { 单独搭 } \\
\text { 配句式 }\end{array}$ & $\begin{array}{l}\text { 事物+由十人+(所) } \\
+ \text { 保持 }\end{array}$ & $\begin{array}{l}\text { 事物 }+V+S+\text { 来+维 } \\
\text { 持 }\end{array}$ \\
\hline
\end{tabular}

\section{5. 语用层面与篇章功能}

\section{1. 语用层面}

从二词搭配的宾语来看, 多是使主体受益, 二词 具有主动、正向积极特性, 只在于积极程度有别, 保 持的积极性高于维持, 但其补语有部分差异:

(11) 贵族的统治权渐渐维持不住了。

（12）小如很专情, 只是每段感情都维持不久。

例 (11)、(12), “维持” 后的结果补语, “不住”、 “不久” 都是负面的结果，但 “保持” 的语料中，没 有负面结果补语的用法。

在语用层面, 二词在理性意义上皆为主动、积极、 正向, 但在感性意义上则区别较明显。当谈到有关心 情、心境, 正面、积极的情绪, 是个人 “保有” 的, 倾向使用 “保持” ; 当提到外在的状态、现象, 则倾 向用 “维持”, 当外在的状态或现象无法持续时, 则用 “维持” 来表达这种负面的结果。

\section{2. 篇章功能}

Halliday (韩礼德) $(1967,1970,1985)$ 提出三种篇 章功能, 即衔接、信息结构和主位结构, 信息结构是 句子内部的篇章组织功能。(陈俊光, 2011)

根据汤廷池（1986）提出汉语基本信息结构 “从 旧到新” 的原则：有些句子成分传达 “旧的” 或 “已 
知的” 信息，而有些句子成分则传达 “新的” 或 “重 要的”信息。最重要的新信息叫做 “信息焦点”。

Chafe (1984, 1994) 提出 “单一新信息制约”, 指在每一个语调单位中新信息只能有一个。( 陈俊光, 2011)

“保持”、“维持” 在篇章功能上, 遵从基本的信 息结构 “从旧到新”之原则，带出其后的新信息。

（13）宗教界对艺术家常保持警戒。

(14) 道德就在法律和宗教间, 维持人群的和谐。

例（13）、（14）“警戒” 及 “人群的和谐” 是由 “保持”、“维持” 带出的宾语, 是句子要传达出的新 信息，也就是该句的“信息焦点”。

当宾语移前时，则情况又不一致。

（15）...要小心不要让身体着凉, 屋里保持温暖。

（16）金钱所带来的满足感只能维持一时。

例（15）“屋里” 是宾语提前, 而成表层主语（深 层宾语), 当主题。根据 “从旧到新” 的信息结构, 主题则是已知的旧信息, “保持” 带出的 “温暖” 为 补语, 是新的信息, 成为本句的信息焦点。

例（16）动词 “维持” 之后, 须遵循单一新信息 制约, 只接一句尾焦点, 不能同时接 “满足感” 和 “一 时” ，避免造成 “宾补争动”。故 “满足感” 须前移 成为主题, 留下句尾焦点 “一时”, 成为 “维持” 带 出的新信息，是全句的信息焦点。

因此, 不论是宾语在后或宾语前移成为主题, 后 留下补语，“保持”、“维持” 的篇章功能都在于带出 该句子的新信息, 也就是引出 “信息焦点”。

\section{6. 国际汉语教学应用之建议}

根据邓守信（2008）的汉语教学语法排序原则, 及参考《语法等级大纲》(1996), “保持”、“维持” 在 《词汇大纲》中分属乙级词、丙级词, 再参照中研院 现代汉语一词泛读网站的统计, 参见表 1, 本文提出 “保持”、“维持”国际汉语教学之排序:

表 10 “保持、维持” 教学排序

\section{一：教 “保持” 后接宾语用法}

1. 讲解基本词义, 介绍基本句型： 主语十保持十宾语

2. 介绍基本句型加上使动用法: $\mathrm{NP}+$ 使十主语十保持十宾语。

3. 介绍经常搭配的词语: 如: 状态、关系、距离、平 衡、纪录, 也倾向搭配心理感受词语。

4. 说明语义重点: 多表过去到现在, 或到未来的持续 状态, 对未来有期许, 具有积极、正向、主动性。

5. 教语用重点: 当说话者要谈到有关心情、心境的时 后, 尤其是正面、积极的情绪, 是个人 “保有” 的, 倾向使用 “保持”。

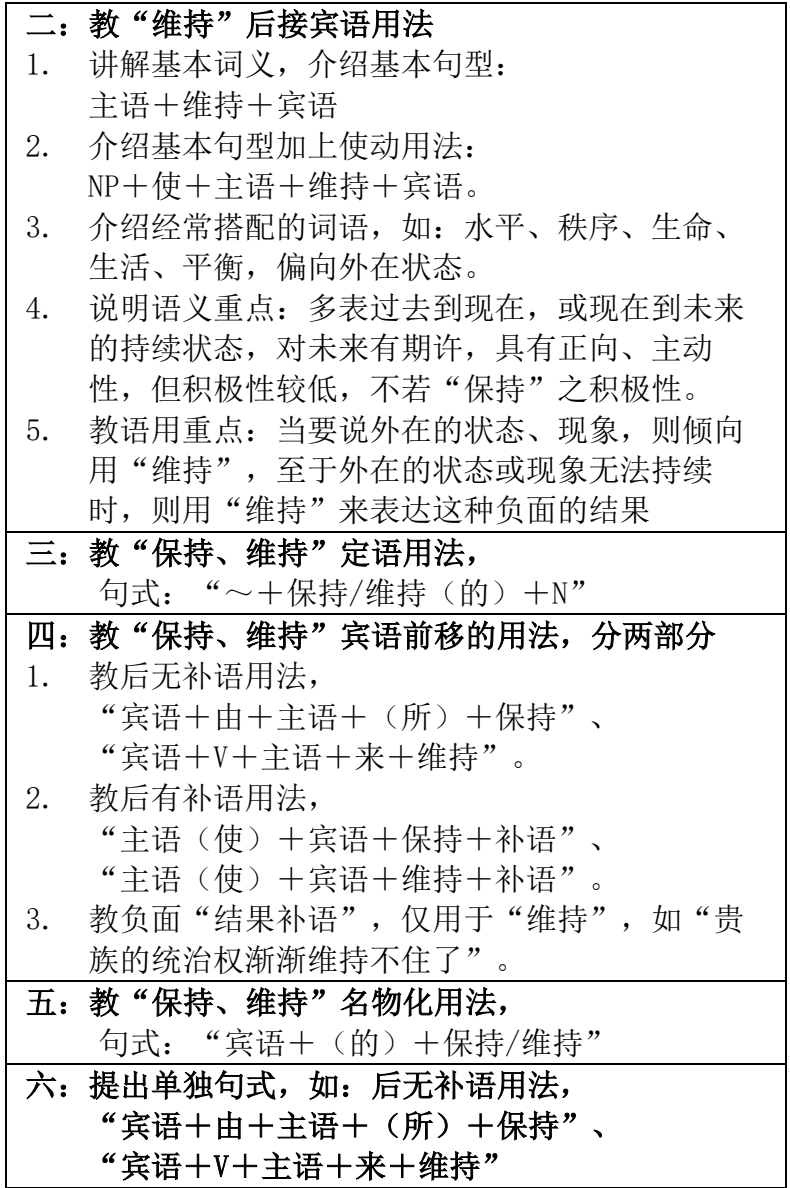

教学或编辑教材时, 可根据表 10 建议之顺序, 还可根据使用者调查结果融入区域词汇使用特性。

\section{7. 结论}

本文探究近义词 “保持”、“维持” 的异同，从句 法、语义、词语搭配等方面着手, 透过语料库的分析, 指出二者的常用句式、单独句式、常搭配之主语、宾 语、语义指向及语义特性之差异等, 再探究二者在语 用层面及篇章功能之别, 再运用前期使用者对比分析 调查结果, 进一步厘清此二词之不同, 使学习者或教 师, 能据此研究结果应用于教学之中。

\section{REFERENCES}

[1] Chen, J. G. (2011) Contrastive Analysis \& Its Applications in Language Pedagogy. Crane Publishing, Taipei.

[2] Deng, S.H. (2009) A Pedagogical Grammar of Chinese. Crane Publishing, Taipei.

[3] Halliday, M. A. K. (1985) An introduction to functional grammar. London; Baltimore.

[4] Tang, T. C. (1986) Mandarin Grammar and Function Explanation: Concurrently Talking about the Comparative Analysis of Mandarin and English Function. Journal of NTNU, 31 : 437-469. 
[5] Chinese WordNet Group. Chinese Word Sketch. http://wordsketch.ling.sinica.edu.tw/.

[6] Institute of Linguistics, Academia Sinica. Sinica

Corpus. http://elearning.ling.sinica.edu.tw/index.html

[7] CCL. Center for Chinese Linguistics PKU. http://ccl.pku.edu.cn:8080/ccl_corpus/ 